\title{
Symptoms of Depression and Associated Risk Factors in Patients with Epilepsy in Burkina Faso
}

\author{
Alfred Anselme Dabilgou1 ${ }^{*}$, Desiré Nanema², Alassane Dravé3 , S. P. Sawadogo1, \\ Julie Marie Adeline Kyelem', Christian Napon", Jean Kaboré1 \\ ${ }^{1}$ Department of Neurology, Yalgado Ouedraogo University Hospital, Ouagadougou, Burkina Faso \\ ${ }^{2}$ Department of Psychiatry, Regional University Teaching Hospital of Ouahigouya, Ouahigouya, Burkina Faso \\ ${ }^{3}$ Department of Neurology, Regional University Teaching Hospital of Ouahigouya, Ouahigouya, Burkina Faso \\ ${ }^{4}$ Department of Neurology, University Teaching Hospital of Bogodogo, Ouagadougou, Burkina Faso \\ Email: *dabilgouanselm@yahoo.fr
}

How to cite this paper: Dabilgou, A. A., Nanema, D., Dravé, A., Sawadogo, S. P., Kyelem, J. M. A., Napon, C., \& Kaboré, J. (2019). Symptoms of Depression and Associated Risk Factors in Patients with Epilepsy in Burkina Faso. Open Journal of Depression, 8 , 29-40.

https://doi.org/10.4236/ojd.2019.81004

Received: January 1, 2019

Accepted: January 29, 2019

Published: February 1, 2019

Copyright $\odot 2019$ by author(s) and Scientific Research Publishing Inc. This work is licensed under the Creative Commons Attribution International License (CC BY 4.0).

http://creativecommons.org/licenses/by/4.0/

\begin{abstract}
Background: Depression is the most common psychiatric disorder in patients with epilepsy. The aim of this study was to determine the prevalence of depressive symptoms and its factors associated in patients with epilepsy at the Yalgado Ouedraogo University Teaching Hospital (Burkina Faso). Methods: This was a prospective 6-month study carried out in Neurology Department from February to July 2017. This study included all the patients with epilepsy aged over 18 years. Sampling was non-random with systematic recruitment. The informed consent of the patient was required. All included patients were assessed using the Hamilton Depression Scale and Gererd questionnaire. The analysis of the data was performed by the software Epi Info version 7. Results: One hundred two patients with epilepsy with a mean age of $41.47 \pm$ 16.67 years were included. The symptoms of depression were present in $67.3 \%$ of patients with epilepsy with a mean age of $42.59 \pm 17$ years, and 78 years (19 - 88 years). Depression was mild in $35 \%$, moderate in $34 \%$ and severe in $31 \%$. The prevalence of depressive symptoms was respectively $57.6 \%$ in male patients and $79 \%$ in female gender. The mean score of HDRS for depression was $15.62 \pm 4.26$. Hypochondriasis (97\%), work and interest (95.5\%) and anxiety-somatic (94.1\%) were the most symptoms of HDRS-17. Higher scores were found for work and interests, anxiety-psychic and hypochondriasis. There was a significant association between perceived stigma, female gender, seizure frequency and presence of depression among patients with epilepsy $(p<0.05)$. Conclusion: Our study had found a high prevalence of depression among patients with epilepsy. High perceived stigma, female
\end{abstract}


gender and seizure frequency were the most associated factors with depressive symptoms.

\section{Keywords}

Epilepsy, Depression, Hamilton Rating Scale of Depression, Risk Factors, Burkina Faso

\section{Introduction}

Epilepsy is one of the most common neurologic illnesses which affect approximately 10 million people annually in sub-Saharan Africa (World Health Organization, 2004). Also, depression is the most common psychiatric disorder in patients with epilepsy (Kanner \& Balabanov, 2002). Patients who have an established diagnosis of epilepsy are at higher risk of developing depression (Tellez-Zenteno et al., 2007; Gaitatzis et al., 2004). The prevalence of depression during entire life of people with epilepsy is estimated between $6 \%$ and $30 \%$ (Kanner, 2003; Jones et al., 2005). Multiple factors are implicated in the development of depression in epilepsy including clinical (seizure frequency, seizure type or foci, epilepsy duration, age at onset, antiepileptic drugs) and psychosocial ones (life stressors, employment, marital status, quality of life) (Titlic et al., 2009). Possible reasons why depression goes unrecognized include patient or physician minimization, atypical presentation, or failure of physician inquiry (Barry et al., 2008). Thus, it is common for clinician that evaluation and management of comorbid psychiatric disorders, like depression in epilepsy patients are the responsibility of psychiatrists (Kanner, 2006). While prevalence of epilepsy is high in Sub-Saharan Africa, there are few studies addressing depression in patients with epilepsy. Especially in Burkina Faso, there are no epidemiological data bases about depression in epilepsy. The aim of this study was to determine the prevalence of depression symptoms and its risks factors among patients with epilepsy (PWE) in hospital setting in Burkina Faso.

\section{Participants and Methods}

\subsection{Participants}

This study was carried during 6 months from February to July 2017 in patients with epilepsy over than 18 years old followed at neurology department of Yalgado Ouedraogo University Teaching Hospital in Burkina Faso. Burkina Faso is a French speaking country located in West Africa which occupies an area of $274.300 \mathrm{~K}$ msq for a population of 16.248 .558 according to the 2006 Burkina population census. The prevalence of epilepsy was 10.6/1000 in 1993 (Debouverie et al., 1993). Youth is the one of fourth main hospitals of the country which received patients referred from peripheral health centers of Burkina Faso. 


\subsection{Inclusion Criteria’s}

Patients whose the duration of following up is less than 3 months, and whose duration of epilepsy is less than 1 year and non-consenting patients were not included in the study.

\section{Sample size and sampling procedures}

The recruitment of patients was systematic and non-randomized. Sample size was calculated using single population proportion formula $[\mathrm{n}=16$ patients $\left.\left(\left(\mathrm{z} \_/ 2\right) 2 \times p \times(1-p)\right) / \mathrm{d} 2\right]$. By considering an assumption of $1.6 \%(0.01)$ proportion of epilepsy in Burkina Faso, the prevalence of depression in patients with epilepsy is unknown in our country, $Z \alpha / 2$ at $95 \%$ CI (1.96), and tolerable margin of error (0.05), the minimum sample size was 16.

\subsection{Assessment of Tool}

We evaluate the presence of depression symptoms by using the Hamilton Depression Rating Scale. The Hamilton Depression Rating Scale (HDRS) was administered to evaluate the level of depression in epilepsy patients (Hamilton, 1960). HDRS consisted of 21 questions but only the first 17 were scored. Eight items are scored on a scale of 0 (not present) to 4 (severe) and nine are scored as 0 - 2. Patients with score 8 or more were classified as being depressed. The severity of depression was graded for both measures using the acceptable standard scoring system: for the HDRS-17: normal-1 - 9 score; mild mood disturbance-10 - 13 score; borderline clinical depression-7 - 20 score; moderate depression-21 - 30 score; severe depression-31 - 40 score; and extreme depression. The definition of epilepsy was the 2017 International League against Epilepsy definition (Scheffer et al., 2017). The duration of epilepsy was calculated as the interval between the date of the first attack ever (corroborated by a close family member) and the first contact with the patient in our neurology clinic. The duration of treatment was calculated as the interval between the first treatment and the first contact with the patient in our neurology clinic. Medication adherence was measured using the self-reported 6-item of Girerd questionnaire, a commonly used and validated instrument (Girerd et al., 2011). The frequency of seizures was defined as described into: 1 ) very frequent (occurring several times a day or at intervals shorter than $7 \mathrm{~d} ; 2$ ) frequent (at intervals longer than $7 \mathrm{~d}$ but shorter than $30 \mathrm{~d}$ ); 3) occasional (at intervals longer than 30 days but shorter than one year; and 4) rare (at intervals longer than one year. Regarding the degree of control on AEDs, patients were considered controlled on AEDs treatment, when seizure free for $\geq 1$ year and were uncontrolled when seizures were frequent, very frequent, occasional or rare. All patients underwent neuroimaging [such as computed tomography $(\mathrm{CT})$ or magnetic resonance imaging (MRI)].

\subsection{Data Collection and Analysis}

The data were collected by an end-of-life medical student trained in administering the Hamilton Scale, Gererd questionnaire and analyzed using of the Epi-info 
version 7 software. In each patient, we collected sociodemographic characteristic (age, sex, profession, martital status, education, residence), characteristics of epilepsy (duration of disease, age at disease onset, EEG, neuroimaging, etiologies, treatment of epilepsy, frequency of seizures and outcome of seizures), draw back social consequences (psychological support, financial support, perceived stigma, perceived of disease) and depression (history of psychiatric disorders, antipsychotic treatments, family history of psychiatric disorders, results of HDRS). The qualitative variables were compared using the Pearson Khi 2 test with a 95\% confidence interval, and the averages were performed using the Student's test. The probability was significant if $p<0.05$.

\subsection{Ethical Considerations}

The study proposal was initially approved by the ethical review board of University of Ouagadougou. A formal letter of permission was obtained from the hospital and submitted to the respective outpatient department. The information about the study was given to the participants. Verbal and then written informed consent was sought for each participant who agreed to participate in the study and full filled the inclusion criteria. Only anonymous Patient informed consent was required prior to inclusion in the study. Patients diagnosed with severe depression were referred to psychiatry department for appropriate management.

\section{Results}

\subsection{Socio-Demographic Characteristics of the Respondents}

One hundred and two patients with a mean age of $41.47 \pm 16.67$ years (Range 19; 88 years) were included in this study. The sample consisted of 59 (57.8\%) male patients and $43(42.1 \%)$ female patients with a sex ratio of 1.37 . According to the working status, 22 (21.5\%) patients were housewives, 18 (17.6\%) civil servants, 17 (16.6\%) farmers and 17 (16.6\%) students. According to educational level, 65 (36.2\%) patients were illiterate, 20 (33.3\%) had secondary level of education. According to marital status, $51.9 \%$ were married, $40.2 \%$ were single. Fifty neigh (57.8\%) patients had living in couple. Sixty five patients (68.6\%) were coming from urban area, 11 (10.7\%) from semi-urban and 26 (25.4\%) patients from rural area.

\subsection{Clinical Characteristics of the Respondents}

The mean duration of disease was 7.01 years (Range 3 - 34 years). The majority of patients ( $n=67 \% ; 65.6 \%)$ had past history of generalized tonic clonic convulsions, while 35 (34.3\%) had focal seizures and one patient had focal and generalized seizures. None patient had acute seizure and history of psychiatric history. Laboratory investigations revealed that $42(41.1 \%)$ patients had done electroencephalography. Of whom, $26 \%$ had focal parttern and $43 \%$ generalized pattern. EEG was normal in $31 \%$ of patients. CT scan was performed in $64(62.7 \%)$ patients and was abnormal in $48(75 \%)$ patients. Patients were treated with one AED in $85.2 \%$ [PB $(n=62 \%$ or $60.7 \%)$, CBZ $(n=24 \%$ or $23.5 \%$, VPA $(n=16 \%$ 
or $15.6 \%)$ ] and bitherapy in $15(86.6 \%)$ patients $[(\mathrm{n}=22 \%$ or $20.95 \%)]$. CBZ was the most AED prescribed in biotherapy ( $\mathrm{n}=12 \%$ or $80 \%)$. The mean duration on AED was 4.08 years ( 3 months - 25 years). The majority of patients ( $n=65 \%$ or $63.7 \%$ ) were uncontrolled (had frequent or very frequent seizures). Almost all of (99\%) patients had a good tolerance of the treatment. According to Girerd questionnaire, adherence of AED was good in 83 (81.3\%) patients, average in 13 $(12.7 \%)$ patients and poor in $6(5.8 \%)$ patients. According to social consequences, ninety eight (96\%) patients had psychological support and 75 (73.5\%) patients had financial support from their family. According to the perception of disease, sixty six (64.7\%) patients had perceived shamed of epilepsy, 44 (43.1\%) had high perceived stigma and 25 (24.5\%) had mystic and diabolic perception of epilepsy.

\subsection{Prevalence of Depression among Epileptic Patients}

Sixty eight patients (67.33\%) with epilepsy had depression (HDRS > 10). The mean age of patients with depression was $42.59 \pm 17.78$ years (Range $19-88$ years). All of them were undiagnosed and untreated before for depression. The depression occurred in the post ictal period in $50(78.13 \%)$ patients. We identified depression symptoms in $57.6 \%$ of male patients and in $79 \%$ of female gender. According to severity, depression was mild in 24 (35\%) patients, moderate in 23 (34\%) and severe in 21 (31\%). patients. Moderate to severe depression was seen in $65 \%$ of patients with epilepsy. The average depression scale was $15.62 \pm 4.26$ points (ranges 10 - 28 points). Table 1 presents the distribution of subtypes of depressive disorders among patients with epilepsy according to HDRS. Hypochondriasis (97\%) was the most symptoms of HDRS-17 followed by work and interest (95.5\%) and anxiety-somatic (94.1\%). Higher scores were found for work and interests, anxiety-psychic, hypochondriasis, depressed mood and anxiety-somatic symptoms. Low scores were obtained for the following items: insight, agitation and genital symptoms. In conclusion, insomnia, anxiety and somatic symptoms were observed respectively in 43 (42.16\%), 88 (86.27\%) and $48(47.06 \%)$ patients.

\subsection{Factors Associated with Depression among People with Epilepsy}

On bivariate analysis, the sociodemographic factors associated with depression ( $p$-value $<0.05)$ were high perceived stigma and female gender $(p=0.02)$. Other variables were not found to be significant risk factors of depression among epileptic patients including marital status $(p>0.05)$, profession $(p=0.32)$, residence $(p=0.55)$, antiepileptic treatment $(p>0.05)$, duration of illness $(p=0.29)$, level of education $(p>0.05)$. Table 2 presents the distribution of study subjects by demographic factors in patients with epilepsy. Social risk factors of depression was respectively financial support $(p=0.004)$ and perceived stigma $(p=$ $0.00000075)$. Table 3 presents the social risk factors of depression among patients with epilepsy. Epileptic factors associated to depression were the occurrence of seizures during the last 3 months $(p=0.0014)$ and uncontrolled seizures $(p=0.002)$. Table 4 presents epilepsy risk factors of depression. 
Table 1. Distribution of subtypes of depressive disorders among depressive patients according to HDRS $(\mathrm{n}=102)$.

\begin{tabular}{cccc}
\hline Item & Depressive disorders & Frequency (\%) & Mean score \\
\hline 1 & Depressed mood & $62(91.1 \%)$ & $1.38 \pm 0.90$ \\
2 & Feelings of guilt & $12(17.6 \%)$ & $0.25 \pm 0.58$ \\
3 & Suicide & $15(22 \%)$ & $0.29 \pm 0.55$ \\
4 & Insomnia-initial & $30(44.1 \%)$ & $0.57 \pm 0.74$ \\
$\mathbf{5}$ & Insomnia-middle & $35(51.4 \%)$ & $1.03 \pm 0.99$ \\
$\mathbf{6}$ & Insomnia-delayed & $20(29.4 \%)$ & $0.41 \pm 0.70$ \\
7 & Work and interests & $65(95.5 \%)$ & $3.28 \pm 1.02$ \\
$\mathbf{8}$ & Retardation & $26(38.2 \%)$ & $0.78 \pm 1.17$ \\
9 & Agitation & $2(3 \%)$ & $0.03 \pm 0.17$ \\
10 & Anxiety-psychic & $63(92.6 \%)$ & $2.17 \pm 0.93$ \\
11 & Anxiety-somatic & $64(94.1 \%)$ & $1.2 \pm 0.53$ \\
12 & Somatic symptoms-gastrointestinal & $32(47 \%)$ & $0.66 \pm 0.75$ \\
13 & Somatic symptoms-general & $36(53 \%)$ & $0.53 \pm 0.53$ \\
14 & Genital symptoms & $3(4.4 \%)$ & $0.04 \pm 0.21$ \\
15 & Hypochondriasis & $66(97 \%)$ & $2.17 \pm 0.62$ \\
16 & Weight loss & $41(60.3 \%)$ & $0.88 \pm 0.82$ \\
17 & Insight & 0 & 0 \\
\hline
\end{tabular}

Table 2. Sociodemographic factors associated to depression $(n=102)$.

\begin{tabular}{|c|c|c|c|c|}
\hline \multirow{2}{*}{ Explanatory variable } & \multicolumn{2}{|c|}{ Symptoms of depression } & \multirow{2}{*}{ OR $(\mathrm{IC}=95 \%)$} & \multirow{2}{*}{$p$ valu } \\
\hline & Yes n (\%) & No $n(\%)$ & & \\
\hline \multicolumn{5}{|l|}{ Age (years) } \\
\hline$\leq 40$ & $37(64.9 \%)$ & $22(37.2 \%)$ & $0.77[0.33 ; 1.80]$ & 0.55 \\
\hline$>40$ & $31(72 \%)$ & $12(27.9 \%)$ & & \\
\hline \multicolumn{5}{|l|}{ Gender } \\
\hline Female & $34(79 \%)$ & $9(20 \%)$ & $2.78[1.13 ; 6.82]$ & 0.02 \\
\hline Male & $34(57.6)$ & $25(42.3 \%)$ & & \\
\hline \multicolumn{5}{|l|}{ Marital status } \\
\hline Married & $35(62.5 \%)$ & $21(37.5 \%)$ & $0.65[28 ; 1.5]$ & 0.3 \\
\hline Divorced & $2(100 \%)$ & 0 & & 0.3 \\
\hline Single & $28(68.2 \%)$ & $13(31.8 \%)$ & $1.3[0.48 ; 2.62]$ & 0.7 \\
\hline \multicolumn{5}{|l|}{ Profession } \\
\hline Employed & $37(62.7 \%)$ & $(37.2 \%)$ & $0.65[0.28 ; 1.52]$ & 0.32 \\
\hline unemployed & $31(72 \%)$ & $12(27.9 \%)$ & & \\
\hline \multicolumn{5}{|l|}{ Area of residence } \\
\hline Urban & $48(68.5 \%)$ & $22(31.4 \%)$ & $0.76[0.32 ; 1.83]$ & 0.55 \\
\hline Rural & $31(72 \%)$ & $21(48.8 \%)$ & & \\
\hline \multicolumn{5}{|l|}{ Level of education } \\
\hline No education & $27(72.9 \%)$ & $10(27 \%)$ & & \\
\hline Primary level & $8(52.9 \%)$ & $8(47 \%)$ & $0.37[0.11 ; 1.26]$ & 0.11 \\
\hline Secondary & $10(70.5 \%)$ & $10(29.4 \%)$ & $0.80[0.27 ; 2.29]$ & 0.67 \\
\hline Superior & $6(57.1 \%)$ & $6(42.8 \%)$ & $0.44[0.12 ; 1.16]$ & 0.22 \\
\hline
\end{tabular}


Table 3. Social risk factors of depression among depressed patients $(n=68)$.

\begin{tabular}{ccccc}
\hline Social support & Number $(\mathbf{n}=\mathbf{6 8})$ & Prevalence (\%) & OR $(\mathrm{IC}=95 \%)$ & $p$ \\
\hline Financial support & & & & \\
Yes & 56 & 74.67 & $3.68[1.47 ; 9.25]$ & 0.004 \\
No & 12 & 44.44 & & \\
Psychological support & & & & 0.79 \\
Yes & 63 & 67.02 & $3.19[0.51 ; 20.09]$ & \\
No & 05 & 62.50 & & \\
Perceveid stigma & & & & \\
Yes & 41 & 93.18 & $15.69[4.36 ; 56.48]$ & 0.00000075 \\
No & 27 & 46.55 & & \\
\hline
\end{tabular}

Table 4. Epilepsy risk factors of depression.

\begin{tabular}{|c|c|c|c|c|}
\hline Epilepsy risk factors & Number $(n=68)$ & Prévalence (\%) & OR $(\mathrm{IC}=95 \%)$ & - \\
\hline \multicolumn{5}{|c|}{ Duration of epilepsy (years) } \\
\hline$<7$ & 49 & 70 & $1.60[0.67 ; 3.82]$ & 0.29 \\
\hline$\geq 7$ & 19 & 59.37 & & \\
\hline \multicolumn{5}{|l|}{$\begin{array}{c}\text { Recent seizures } \\
\text { (past } 3 \text { months ago) }\end{array}$} \\
\hline Yes & 50 & 78.13 & $3.97[1.67 ; 9.47]$ & 0.0014 \\
\hline no & 18 & 47.37 & & \\
\hline \multicolumn{5}{|l|}{ Seizures types } \\
\hline Generelized & 44 & 65.67 & $0.88[0.37 ; 2.10]$ & 0.7680 \\
\hline Focale & 24 & 68.57 & & \\
\hline \multicolumn{5}{|l|}{ Type of treatment } \\
\hline Monotherapy & 55 & 63.22 & $3.78[0.80 ; 17.84]$ & 0.075 \\
\hline Dual therapy & 13 & 86.67 & & \\
\hline \multicolumn{5}{|c|}{ Type of AED on monotherapy } \\
\hline Phenobarbital & 34 & 61.82 & $0.62[0.27 ; 1.43]$ & 0.26 \\
\hline Carbamazepine & 8 & 47 & $0.37[0.13 ; 1.06]$ & 0.06 \\
\hline Sodium valproate & 10 & 83.33 & $2.76[0.57 ; 13.37]$ & 0.19 \\
\hline Clonazepam & 1 & 50 & $0.49[0.03 ; 8.12]$ & 0.61 \\
\hline Lamotrigine & 1 & 100 & 0 & 0.48 \\
\hline \multicolumn{5}{|l|}{ Adherence of treatment } \\
\hline Good & 51 & 63.75 & $1.52[0.37 ; 6.18]$ & 0.97 \\
\hline Moderate & 8 & 72.72 & & 0.56 \\
\hline $\mathrm{Bad}$ & 6 & 100 & & \\
\hline \multicolumn{5}{|l|}{ Seizures controlled } \\
\hline Yes & 17 & 45.95 & $0.23[0.09 ; 0.56]$ & 0.0008 \\
\hline No & 51 & 78.46 & & \\
\hline
\end{tabular}




\section{Discussion}

The aim of this study was to assess the prevalence of depression and its associated factors among patients with epilepsy on follow up at Youth of Ouagadougou according to Hamilton Depression Rating Scale, an international validated tool.

\subsection{Sociodemographic of Respondents}

Our study had showed a high prevalence of depression among patients with epilepsy (63.3\%). Similar prevalence was observed in several studies from Asia: 60\% in India and Paskistan (Pandian \& Mohan, 2015; Yousafzai et al., 2009) and 63\% in Korea (Lee et al., 2010). In comparison with others studies in Sub Africa, the prevalence of depression was low than in the study of Onwuekwe (Onwuekwe et al., 2012) in Nigeria (85\%), but higher than others studies (Owolabi et al., 2016; Tsegabrhan et al., 2014) in which the prevalence was ranging from $20.4 \%$ to $49.3 \%$. According to literature (Barry, 2003), high prevalence of depression is probably due to the lack of acceptance of the diagnosis of epilepsy. In our study $24.5 \%$ of patients had mystic and diabolic perception of epilepsy for many patients; epilepsy is due to sociocultural features. The differences of prevalence between the studies are possibly due to the different methodology in different studies including method of patient selection (e.g. hospital or community based), the method of evaluation for depression (different scales) and sociocultural characteristics of population study.

\subsection{Clinical Presentation of Depressive Symptoms}

Depression was moderate to severe in the majority of depressed patients in our study (65\%), in line with the studies of Hamed in Egypt with 78.43\% (Hamed et al., 2012b). and Tsegabrhan et al. in Ethiopia with 60.1\% (Tsegabrhan et al., 2014) but in contrast with Nidhinandana et al. in India (Nidhinandana et al., 2007) who had found a majority of patients with mild depression (65.2\%). Hypochondriasis is the most symptom of depression seen in $97 \%$ of depressed patients. Suicidal ideation was observed in only $22 \%$ of this patients, in line with studies from Ethiopia with 29.8\% (Haile et al., 2018) and Egypt with 23.5\% (Hamed et al., 2012a) but higher than in literature (Jones et al., 2003), Andrijić in Bosnia (Andrijić et al., 2014) with 14\% and in USA (Hecimovic et al., 2012) with $11.9 \%$. In opposition, highest prevalence of suicidal ideation was observed in studies from Cuba Havana with 45.2\% (Espinosa et al., 2010) and Egypt with 55\% (Hamed et al., 2012b). Furthermore, in Cuba Havana, study subjects were patients with temporal lobe epilepsy, but our study included all people living with epilepsy followed in neurology department. Thus, the presence of suicidal ideation should prompt immediate referral (Kanner, 2003).

\subsection{Associated Factors of Depression}

According to the perception of disease, about forty three percent of our study population (43.1\%) had high perceived stigma. High perceived stigma was asso- 
ciated with the development of depression, in line with several studies in African setting, as showed in the study of Bifftu (Biffu et al., 2015) and Adewuya in Nigeria (Adewuya \& Ola, 2005). Social stigma is due to the danger and unpredictability of the illness, and the psychotropic effects of antiepileptic drugs (Mula \& Schmitz, 2009). Female gender was associated to depression symptoms in our study, in line with literature (Hamed et al., 2012b; Thomsonand \& Brennenstuhl, 2009). In contrast, male gender was significally depression than women in the study of Yousafzai (Yousafzai et al., 2009). As in several studies, we did not found differences between marital status and depression (Thomsonand \& Brennenstuhl, 2009; Zahiroddin et al., 2008), age and depression (Nidhinandana et al., 2007; Asadi-Pooya \& Sperling, 2011), level of education and depression (Thomsonand \& Brennenstuhl, 2009; Kutlu et al., 2010). Epilepsy-related factors associated with the development of depression in PWE were occurring of recent seizures in the last 3 months and uncontrolled seizures were associated to depression $(p<0.05)$. These features are in line with several researchers according to uncontrolled seizures (Hamed et al., 2012a; Ogunrin \& Obiabo, 2010). Burkina Faso lacks the person power and infrastructure to manage epilepsy well for the majority of patients in need. For example, for a country of almost 16 million people, Burkina Faso has only 9 neurologists, 3 neurosurgeons and approximately 13 psychiatrists. The most of these heath workers are concentrated in the capital city, Ouagadougou. According to seizures frequency, having recent seizures is a risk factor of depression (Owolabi et al., 2016; Tsegabrhan et al., 2014; Biffu et al., 2015). Seizure frequency of less than 1 per month predicted postictal depression (Andrijić et al., 2014). In our study, AEDs were not associated with depression. According to literature, phenobarbital and other barbiturates have long been associated with increased risk of depression and suicide (Barry, 2003; Miller et al., 2008; Salzberg \& Vajda, 2001). In our study, phenobarbital was the most prescribed drug $(60.7 \%)$.

\section{Limitations of the Study}

This intra-hospital study had several limitations. In this study we included only patients from a tertiary care center. These subjects might not be representative epilepsy patients in general population. The administration of the Hamilton scale was done in French while about $30 \%$ of the population study was not solarized.

\section{Conclusion}

In our study, depression occurred in two third of population study consisting of young patients without history of depression. Depression was moderated to severe in the majority of depressed patients. Female gender, having high perceived stigma, uncontrolled seizures and having recent seizures were associated with depressive symptoms. This study showed the necessity to have multidisciplinary care, involving neurologists, neurosurgeons and psychiatrists. 


\section{Acknowledgements}

We wish to thank Mr. P David Koura, M.Sc. for valuable comments on a former version of this paper.

\section{Conflicts of Interest}

With regard to the present study none of the authors has to disclose conflicts of interest.

\section{Funding}

No funding.

\section{References}

Adewuya, A. O., \& Ola, B. A. (2005). Prevalence of and Risk Factors for Anxiety and depressive Disorders in Nigerian Adolescents with Epilepsy. Epilepsy Behavior, 6, 342-347. https://doi.org/10.1016/j.yebeh.2004.12.011

Andrijić, N. L., Alajbegović, A., Zec, S. L., \& Loga, S. (2014). Suicidal Ideation and Thoughts of Death in Epilepsy Patients. Psychiatria Danubina, 26, 52-55.

Asadi-Pooya, A., \& Sperling, M. R. (2011). Depression and Anxiety in Patients with Epilepsy, with or without Other Chronic Disorders. Iranian Red Crescent Medical Journal, 13, 112-116.

Barry, J. J. (2003). The Recognition and Management of Mood Disorders as a Comorbidity of Epilepsy. Epilespia, 44, 30-40. https://doi.org/10.1046/j.1528-1157.44.s4.4.x

Barry, J.J., Ettinger, A. B., Friel, P. et al. (2008). Consensus Statement: The Evaluation and Treatment of People with Epilepsy and Affective Disorders. Epilepsy \& Behavior, 13, S1-S29. https://doi.org/10.1016/j.yebeh.2008.04.005

Biffu, B. B., Dachew, B. A., Tiruneh, B. T., \& Tebeje, N. B. (2015). Depression among People with Epilepsy in Northwest Ethiopia: A Cross-Sectional Institution Based Study. BMC Research Notes, 8, 585. https://doi.org/10.1186/s13104-015-1515-Z

Debouverie, M., Kaboré, J., \& Dumas, M. (1993). Epidémiologie de l'épilepsie au Burkina Faso à propos d'une enquête en milieu rural. Neurologie tropicale. In AUPELF-UREF (Ed.), (pp. 57-61). Paris: John Eurotext.

Espinosa, A. G., Machado, R. A., González, S. B. et al. (2010). Wisconsin Card Sorting Test Performance and Impulsivity in Patients with Temporal Lobe Epilepsy: Suicidal Risk and Suicide Attempts. Epilepsy \& Behavior, 17, 39-45.

https://doi.org/10.1016/j.yebeh.2009.09.010

Gaitatzis, A., Trimple, M. R., \& Sander, J. W. (2004). The Psychiatric Comorbidity of Epilepsy. Acta Neurologica Scandinavica, 110, 207-220.

https://doi.org/10.1111/j.1600-0404.2004.00324.x

Girerd, X., Radauceanu, A., Achard, J. M. et al. (2011). Evaluation de l'observance par l'interrogatoire au cours du suivi des hypertendus dans des consultations spécialisées. Archives des Maladies du Coeur et des Vaisseaux, 94, 839-842.

Haile, K., Awoke, T., Ayano, G., Tareke, M., Abate, A., \& Nega, M. (2018). Suicide Ideation and Attempts among People with Epilepsy in Addis Ababa, Ethiopia. Annals of General Psychiatry, 17, 4. https://doi.org/10.1186/s12991-018-0174-6

Hamed, S. A., Elserogy, Y. B., Abdou, M. A., \& Abdellah, M. M. (2012a). Risks of Suici- 
dality in Adult Patients with Epilepsy. World Journal of Psychiatry, 2, 33-42. https://doi.org/10.5498/wjp.v2.i2.33

Hamed, S. A., Metwaly, N. A. H., Hassan, M. M. et al. (2012b). Depression in Adults with Epilepsy: Relationship to Psychobiological Variables. World Journal of Neurology, 2, 1-10. https://doi.org/10.5316/wjn.v2.i1.1

Hamilton, M. (1960). A Rating Scale for Depression. Journal of Neurology, Neurosurgery, and Psychiatry, 23, 56-62, https://doi.org/10.1136/jnnp.23.1.56

Hecimovic, H., Santos, J. M., Carter, J. et al. (2012). Depression but Not Seizure Factors or Quality of Life Predicts Suicidality in Epilepsy. Epilepsy \& Behavior, 24, 426-429. https://doi.org/10.1016/j.yebeh.2012.05.005

Jones, J. E., Hermann, B. P., Barry, J. J. et al. (2003). Rates and Risk Factors for Suicide, Suicidal Ideation, and Suicide Attempts in Chronic Epilepsy. Epilepsy \& Behavior, 4, S31-S38. https://doi.org/10.1016/j.yebeh.2003.08.019

Jones, J. E., Hermann, B. P., Barry, J. J. et al. (2005). Clinical Assessment of Axis I Psychiatric Morbidity in Chronic Epilepsy: A Multicenter Investigation. The Journal of Neuropsychiatry and Clinical Neurosciences, 17, 172-179.

https://doi.org/10.1176/jnp.17.2.172

Kanner, A. M. (2003). Depression in Epilepsy: Prevalence, Clinical Semiology, Pathogenic Mechanisms, and Treatment. Biological Psychiatry, 54, 388-398.

https://doi.org/10.1016/S0006-3223(03)00469-4

Kanner, A. M. (2006). Depression and Epilepsy: A New Perspective on Two Closely Related Disorders. Epilepsy Currents, 6, 141-146. https://doi.org/10.1111/j.1535-7511.2006.00125.x

Kanner, A. M., \& Balabanov, A. (2002). Depression and Epilepsy: How Closely Related Are They? Neurology, 58, 27-39. https://doi.org/10.1212/WNL.58.8_suppl_5.S27

Kutlu, A., Başaran, Ş., \& Altun, N. S., \& Ünalan, H. (2010). Quality of Life, Depression and Anxiety in Patients with Epilepsy: Controlled Study with Short Form 36 Questionnaire, Beck Depression Inventory, and Hamilton Anxiety Scale. Neurosurgery Quarterly, 20, 95-99.

Lee, S.-A., Lee, S.-M., \& No, Y.-O. (2010). Factors Contributing to Depression in Patients with Epilepsy. Epilepsia, 51, 1305-1308. https://doi.org/10.1111/j.1528-1167.2009.02387.x

Miller, J. M., Kustra, R. P., Vuong, A., Hammer, A. E., \& Messenheimer, J. A. (2008). Depressive Symptoms in Epilepsy: Prevalence, Impact, Aetiology, Biological Correlates and Effect of Treatment with Antiepileptic Drugs. Drugs, 68, 1493-1509.

https://doi.org/10.2165/00003495-200868110-00003

Mula, M., \& Schmitz, B. (2009). Depression in Epilepsy: Mechanisms and Therapeutic Approach. Therapeutic Advances in Neurological Disorders, 2, 337-344. https://doi.org/10.1177/1756285609337340

Nidhinandana, S., Chinvarun, Y., \& Sithinamsuwan, P. et al. (2007). Prevalence of Depression among Epileptic Patients at Phramongkutklao Hospital. Journal of the Medical Association of Thailand, 90, 32-36.

Ogunrin, O. A., \& Obiabo, Y. O. (2010). Depressive Symptoms in Patients with Epilepsy: Analysis of Self-Rating and Physician's Assessment. Neurology India, 58, 565-570. https://doi.org/10.4103/0028-3886.68679

Onwuekwe, I. O., Ekenze, O. S., Bzeala-Adikaibe, O. S., \& Ejekwu, J. U. (2012). Depression in Patients with Epilepsy: A Study from Enugu, South East Nigeria. Annals of Medical and Health Science Research, 2, 10-13. 
https://doi.org/10.4103/2141-9248.96929

Owolabi, S. D., Owolabi, L. F., Udofia, O., \& Sale , S. (2016). Depression in Patients with Epilepsy in Northwestern Nigeria: Prevalence and Clinical Correlates. Annals of African Medicine, 15, 179. https://doi.org/10.4103/1596-3519.194279

Pandian, G. B., \& Mohan, A. (2015). Study on Prevalence of Depression and Adverse Drug Reactions among South Indian Epileptic Patients. Asian Journal of Pharmaceutical and Clinical Research, 8, 73-76.

Salzberg, M. R., \& Vajda, F. J. (2001). Epilepsy, Depression and Antidepressant Drugs. Journal of Clinical Neuroscience, 8, 209-215. https://doi.org/10.1054/jocn.2000.0896

Scheffer, I. E., Berkovic, S., Capovilla, G. et al. (2017). Classification of the Epilepsies; Position Paper of the ILAE Commission for Classification and Terminology. Epilepsia, 58, 512-521. https://doi.org/10.1111/epi.13709

Tellez-Zenteno, J. F., Patten, S. B., Jetté, N., Williams, J., \& Wiebe, S. (2007). Psychiatric Comorbidity in Epilepsy: A Population-Based Analysis. Epilepsia, 48, 2336-2344. https://doi.org/10.1111/j.1528-1167.2007.01222.x

Thomsonand, E., \& Brennenstuhl, S. (2009). The Association between Depression and Epilepsy in a Nationally Representative Sample. Epilepsia, 50, 1051-1058.

Titlic, M., Basic, S., Hajnsek, S., \& Lusic, I. (2009). Comorbidity Psychiatric Disorders in Epilepsy: A Review of Literature. Bratislavske Lekarske Listy, 110, 105-109.

Tsegabrhan, H., Negash, A., \& Tesfay, K. (2014). Co-Morbidity of Depression and Epilepsy in Jimma University Specialized Hospital, Southwest Ethiopia. Neurology India, $62,649$.

World Health Organization (2004). Epilepsy in the WHO African Region. Hoofdorp: Bridging the Gap, Paswerk Bedrijven.

Yousafzai, A. R., Yousafzai, A. W., \& Taj, R. (2009). Frequency of Depression in Epilepsy: A Hospital Based Study. Journal of Ayub Medical College Abbottabad, 21, 73-75.

Zahiroddin, A. R., Shafiee Kandjani, A. R., \& Ghoreishi, F. (2008). Depression Rate among 18-40-Year-Old Patients Suffering from Generalized Tonic-Clonic Epilepsy Referred to Neurology Clinics in an Iranian Hospital. Neurosciences (Riyadh), 13, 86-87.

\section{List of Abbreviations}

AED: antiepileptic drug

PB: phenobarbital

CBZ: carbamazepine 